\title{
Crisis Management or Crisis Preparedness? The Importance of Economic Diversification in Building Resilience to Economic Crises
}

\author{
Zizi Goschin ${ }^{1}$ \\ ${ }^{1}$ The Bucharest University of Economic Studies and Institute of National Economy, Bucharest, Romania
}

\begin{abstract}
.
Economic crises periodically disrupt the economic activity, severely putting to test the resilience capacity, and the ability to overcome hardships by adapting and changing. This happens everywhere, from micro (firm) level to macro (country/region) level alike. A large and continuously growing literature was dedicated to understanding the reasons behind the crises, their mechanism, effects and, most of all, the solutions. What if the answer lies not in solving the crisis after it started but in preventing, or at least preparing in advance for economic shocks by building resilience during good times, so that the impact of economic crises can be attenuated? Starting from these considerations, the paper focuses on regional economic specialization and its opposite - economic diversification, two business strategies already acknowledged in the literature as relevant factors for the capacity to mitigate economic crises. We tested the hypothesis of resilience-inducing economic diversification in the Romanian economy, using NUTS3 level data and found that more diversified regional economies were better at coping with the hardships triggered by the recent recession.
\end{abstract}

Keywords: specialization; economic resilience; spatial model; regional 


\section{Introduction}

Preparedness for economic shocks means creating an economic environment that helps to mitigate crisis-induced adversities and respond faster to economic hardships. One such helpful action is believed to be the pursuit of business diversification as a way of reducing vulnerability and risk associated with dependence on one or a few economic activities. At regional level, this creates a balanced economy, able to harvest regional strengths without relying too heavily on a limited number of economic sectors.

The theoretical framework of our research draws on recent regional resilience literature which aims at identifying the particular spatial characteristics of regions that are better shock absorbers (Bristow, 2010; Davies, 2011; Di Caro, 2017; Fingleton et al., 2015; Cowell, 2013). Resilience is based on three pillars: absorption, adaptation, and transformation. The drivers of resilience are related to advantageous industrial and business structure, efficient labour market, favourable financial arrangements, good agency and decision-making. In this context, economic diversity is considered a key factor for resilience since it promotes higher flexibility and adaptability, helps dispersing the risks and enables regions to cope more easily with economic distress. Diversification supports more rapid adjustment to the changing economic environment during a crisis.

Economists have long asserted that economic growth is closely linked to producing a larger diversity of goods and services (Kuznets, 1971; Grossman and Helpman, 1992). Likewise, regional scholars believe that diversity can enhance the economic potential of regions (e.g. Dissart, 2003; Pede, 2013), encouraging innovations, competitivity and ultimately economic growth (Knott, 2003; Wennekers \& Thurik, 1999). Nevertheless, the relation between diversification and resilience to economic shocks is not straightforward. Economic diversity has both advantages and limits (Duranton and Puga, 1999) and its effects on regional resilience are yet to be indefeasibly proven. On one hand, its strengths consist in the ability to reducing, distributing and diversifying risks, avoiding vulnerability to decline in a dominant industry, extending growth opportunities to more sectors of activity and enlarging the knowledge base of the regional economy; it also underpins stability by reining in economic fluctuations and preventing unemployment rise. Concepts such as "Jacobian externalities" (Jacobs, 1969) legitimise diversification based on the benefits brought about by knowledge spillovers generated by diversified economic activities in a region (Feldman and Audretsch, 1999).

On the other hand, while specialization means focusing on a limited number of activities, thus gaining expertise and increasing productivity, diversification inherently limits such benefits. Moreover, some studies challenged the belief that specialization is altogether bad for regional development and resilience to crisis. For instance, the empirical research of Cuadrado-Roura and Maroto (2016) indicated that specialisation in productive sub-industries helps rapid recovery from economic shocks. Reconciling the pro- and anti-specialization theories, Imbs and Wacziarg (2003) describe a U-curve link between specialization and economic growth. They found that after a point of minimum specialization (or maximum diversification), high developed counties turn back to the specialization path, concentrating on advanced, high-tech activities. 


\section{International conference on Research in MANAGEMENT}

Starting from these general considerations and given the lack of consensus in the literature, our goal is to investigate the influence of regional specialization on economic resilience in the context of the most recent crisis, focusing on Romania as a case study. We adopt a regional

scale of analysis, namely NUTS3 regions and use specific spatial econometrics tools. Spatial homogeneity, theoretically hypothesised in most regional studies, is often breached by real data, causing autocorrelation issues. Given the potential for serial correlation in our data, we decided to use both classic and spatial regression models. The latter account for spatial dependence in the database and allow for a deeper understanding of spatial interactions among regions.

\section{Methods, variables and data}

There are various indicators and methods for studying economic diversity and its relationship with economic development. These range from rather simple metrics (Wagner, 2000), based on the structure of employment or value added, to more complex methods such as regional input-output analysis (Wagner \& Deller, 1998) and spatial regressions (Pede, 2013).

Our study uses three standard measures of specialization/diversification, namely the location quotient (Florence, 1939), the Herfindahl-Hirschman index (Hirschman, 1964) and the Krugman dissimilarity index (Krugman, 1991).

Location quotients (LQ) compare the specialization rate of region $i$ in industry $j\left(g_{i j}\right)$ with the national economy's average specialisation in the same industry $\mathrm{j}\left(\mathrm{g}_{\mathrm{j}}\right)$ :

$$
L Q_{i j}=\frac{X_{i j} / X_{i}}{X_{j} / X}=\frac{g_{i j}}{g_{j}}
$$

where $\mathrm{X}$ is a relevant economic indicator, usually GDP or employment. Values above 1 indicate the industries playing a higher than average role in the region's economy.

The Herfindahl-Hirschman index measures overall absolute specialization by summing the squared shares of all economic sectors $\mathrm{j}$ in the regional economy $\mathrm{i}\left(\mathrm{g}_{\mathrm{ij}}\right)$, as follows:

$$
\mathrm{H}_{\mathrm{i}}^{\mathrm{S}}=\sum_{\mathrm{j}=1}^{\mathrm{m}}\left(\mathrm{g}_{\mathrm{ij}}^{\mathrm{S}}\right)^{2}
$$

The bigger the index, the higher the specialization level.

The Krugman dissimilarity index compares the shares of all industries $\mathrm{j}$ in region $\mathrm{i}\left(\mathrm{g}_{\mathrm{ij}}\right)$ with their corresponding shares in the national economy $\left(\mathrm{g}_{\mathrm{j}}\right)$ :

$$
\mathrm{K}_{\mathrm{i}}^{\mathrm{S}}=\sum_{\mathrm{j}=1}^{\mathrm{m}}\left|\mathrm{g}_{\mathrm{ij}}^{\mathrm{S}}-\mathrm{g}_{\mathrm{j}}\right|
$$

The bigger the index, the higher is the region's dissimilarity with the economic structure of national economy. 


\section{International conference on Research in MANAGEMENT}

These three specialization measures will be further used as explanatory variables for the regional resilience/weakness to economic crises in the framework of spatial models.

Given the spatial structure of the data, we need to test for possible spatial interactions among neighbours, which might affect the regression model. Potential spatial autocorrelation

is usually detected with a basic indicator in spatial statistics, namely Moran's I (Moran, 1950):

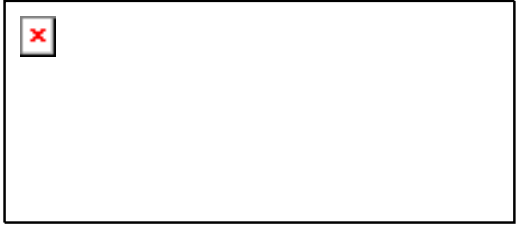

where the spatial weight $w_{i j}$ is 1 if regions $i$ and $j$ are neighbours, and 0 otherwise. The spatial weights matrix $\mathrm{W}$ hence describes the spatial structure by identifying the regions that are connected (i.e. neighbours). In this paper we use contiguity matrices (neighbourhood is based on common borders) of type Queen I (first order neighbours) and II (first and second order neighbours). The higher the absolute value of Moran's $I$, the stronger the similarity among neighbour regions.

If spatial dependence is detected, it needs to be addressed by means of spatial modelling (Anselin et al., 2006). To this end, we use spatial variables, in two forms. Firstly, we test a spatial autoregressive model that includes a spatial lag of the dependent variable $y$ in the regression specification, as follows:

$$
Y=\rho W Y+X \beta+\varepsilon
$$

Secondly, we estimate a spatial error model, containing an autoregressive type of errors $\varepsilon$ :

$$
Y=\alpha+X \beta+\varepsilon, \text { where } \varepsilon=\lambda W \varepsilon+v
$$

where $\mathrm{W}$ is a spatial weights matrix, $\mathrm{Wy}$ is the spatial lag of the dependent variable $\mathrm{y}$ (measuring the average value of $\mathrm{y}$ for the neighbouring regions) and $\mathrm{X}$ is the matrix of regressors. The final choice of the appropriate model for our data is based on Lagrange multiplier tests and other standard statistical guidelines.

Variables and data. The dependent variable in our models is regional weakness to economic crises, proxied by two custom-made indicators. The first one builds on GDP dynamics during the most recent economic crisis (2008-2010) and is computed as a ratio between the percentage decline in GDP of region $\mathrm{i}$ and percentage decline in average (national) GDP. Values above 1 indicate the vulnerable regions, being more adversely affected by the international economic crisis, while values below 1 point to more resilient regions. The second dependent variable represents an alternative measurement of economic vulnerability, based on employment instead of GDP, while using the same computational formula. 


\section{International conference on Research in MANAGEMENT}

The variable of interest is regional economic specialization/diversification, measured with the specialization indices Herfindahl and Krugman, as well as the location quotients for the main economic sectors (agriculture, manufacturing and trade). We are using civil employment data issued by the National Institute of Statistics. The spatial structure is addressed at NUTS 3 level, i.e. the 41 Romanian counties and Bucharest Municipality. The sectoral dimension is represented by 16 major economic sectors: Agriculture, forestry and fishing; Manufacturing; Mining and quarrying; Electricity, gas, steam and air conditioning; Construction; Wholesale

and retail trade; Transportation and storage services; Accommodation and food service activities; Information and communication services; Professional, scientific and technical activities; Services; Public administration and defence; Social insurance from the public system, administrative and support service activities; Education; Health and social care; Water supply; Sewerage, waste management and remediation activities.

The control variables account for many potential factors of influence on regional resilience to economic crises and capture the situation before the crisis (i.e. the year 2008, since the outbreak of the crisis in Romania took place in the last quarter of this year): GDP per capita as proxy for the regional development level; average monthly wage and unemployment rate (\%) as proxy for labour market performance; gross investments per capita and foreign direct investments per capita, both reflecting the potential for economic growth; number of graduates from tertiary education per 1000 inhabitants as proxy for human capital; urbanization rate (\% of urban population in the county) and industrialization rate of the county (\% of employment in industry) as alternative proxies for regional development level. They are all expressed in logarithms, except for the rates.

\section{Results and Discussion}

The specialization indices presented in Table 1 reveal high variation among Romanian counties: for instance, in 2008 the absolute (Herfindahl) index ranged from 0.105 in Bucharest municipality to 0.329 in Teleorman, while relative (Krugman) index varied from 0.109 in Braila to 0.563 in Teleorman. In general, the economic specialization is negatively corelated with the development level of the counties, in agreement with previous empirical findings for Romania (e.g., Trăistaru and Păuna, 2003; Andrei et al., 2007).

Table 1. Specialization indices

\begin{tabular}{|l|c|c|c|c|c|c|c|c|}
\hline \multirow{2}{*}{ County } & \multicolumn{4}{|c|}{ Herfindahl index } & \multicolumn{4}{c|}{ Krugman index } \\
\cline { 2 - 10 } & 2008 & 2009 & 2010 & 2017 & 2008 & 2009 & 2010 & 2017 \\
\hline Alba & 0.186 & 0.186 & 0.185 & 0.176 & 0.196 & 0.195 & 0.185 & 0.239 \\
\hline Arad & 0.171 & 0.168 & 0.172 & 0.178 & 0.245 & 0.261 & 0.279 & 0.285 \\
\hline Arges & 0.174 & 0.174 & 0.178 & 0.170 & 0.168 & 0.155 & 0.168 & 0.225 \\
\hline Bacau & 0.158 & 0.160 & 0.165 & 0.143 & 0.143 & 0.144 & 0.156 & 0.206 \\
\hline Bihor & 0.179 & 0.179 & 0.187 & 0.159 & 0.152 & 0.164 & 0.180 & 0.187 \\
\hline Bistrita-Nasaud & 0.194 & 0.193 & 0.189 & 0.173 & 0.199 & 0.189 & 0.175 & 0.244 \\
\hline Botosani & 0.285 & 0.293 & 0.297 & 0.222 & 0.454 & 0.448 & 0.444 & 0.413 \\
\hline Braila & 0.163 & 0.164 & 0.165 & 0.149 & 0.109 & 0.116 & 0.114 & 0.172 \\
\hline Brasov & 0.132 & 0.126 & 0.124 & 0.135 & 0.328 & 0.325 & 0.332 & 0.265 \\
\hline Buzau & 0.228 & 0.229 & 0.240 & 0.189 & 0.275 & 0.261 & 0.284 & 0.283 \\
\hline Calarasi & 0.260 & 0.275 & 0.283 & 0.221 & 0.407 & 0.432 & 0.451 & 0.424 \\
\hline Caras-Severin & 0.181 & 0.187 & 0.192 & 0.158 & 0.167 & 0.192 & 0.193 & 0.204 \\
\hline
\end{tabular}




\section{International conference on Research in MANAGEMENT}

Budapest, Hungary

\begin{tabular}{|l|l|l|l|l|l|l|l|l|}
\hline Cluj & 0.133 & 0.129 & 0.127 & 0.113 & 0.161 & 0.160 & 0.172 & 0.153 \\
\hline Constanta & 0.118 & 0.118 & 0.120 & 0.111 & 0.284 & 0.284 & 0.280 & 0.276 \\
\hline Covasna & 0.182 & 0.177 & 0.181 & 0.166 & 0.216 & 0.199 & 0.223 & 0.219 \\
\hline Dambovita & 0.198 & 0.202 & 0.205 & 0.176 & 0.230 & 0.243 & 0.253 & 0.268 \\
\hline Dolj & 0.203 & 0.213 & 0.225 & 0.161 & 0.238 & 0.256 & 0.283 & 0.249 \\
\hline Galati & 0.154 & 0.157 & 0.162 & 0.130 & 0.077 & 0.109 & 0.127 & 0.144 \\
\hline Giurgiu & 0.290 & 0.300 & 0.311 & 0.212 & 0.504 & 0.494 & 0.508 & 0.509 \\
\hline Gorj & 0.135 & 0.135 & 0.136 & 0.117 & 0.333 & 0.341 & 0.349 & 0.337 \\
\hline Harghita & 0.187 & 0.187 & 0.189 & 0.157 & 0.201 & 0.205 & 0.197 & 0.180 \\
\hline Hunedoara & 0.134 & 0.134 & 0.138 & 0.138 & 0.214 & 0.223 & 0.236 & 0.201 \\
\hline Ialomita & 0.243 & 0.248 & 0.251 & 0.195 & 0.337 & 0.337 & 0.332 & 0.337 \\
\hline Iasi & 0.159 & 0.162 & 0.168 & 0.123 & 0.179 & 0.185 & 0.200 & 0.190 \\
\hline Ilfov & 0.149 & 0.150 & 0.150 & 0.134 & 0.330 & 0.348 & 0.357 & 0.335 \\
\hline Maramures & 0.208 & 0.209 & 0.211 & 0.177 & 0.246 & 0.251 & 0.250 & 0.261 \\
\hline Mehedinti & 0.230 & 0.245 & 0.250 & 0.188 & 0.348 & 0.369 & 0.379 & 0.365 \\
\hline $\begin{array}{l}\text { Bucharest } \\
\text { municipality }\end{array}$ & 0.105 & 0.104 & 0.102 & 0.104 & 0.704 & 0.706 & 0.727 & 0.648 \\
\hline Mures & 0.165 & 0.164 & 0.167 & 0.143 & 0.136 & 0.127 & 0.125 & 0.127 \\
\hline Neamt & 0.236 & 0.243 & 0.244 & 0.188 & 0.301 & 0.303 & 0.302 & 0.287 \\
\hline Olt & 0.255 & 0.269 & 0.278 & 0.209 & 0.347 & 0.375 & 0.390 & 0.350 \\
\hline Prahova & 0.146 & 0.140 & 0.139 & 0.139 & 0.212 & 0.198 & 0.201 & 0.175 \\
\hline Salaj & 0.203 & 0.201 & 0.199 & 0.168 & 0.243 & 0.232 & 0.219 & 0.226 \\
\hline Satu Mare & 0.211 & 0.212 & 0.215 & 0.172 & 0.265 & 0.260 & 0.265 & 0.238 \\
\hline Sibiu & 0.150 & 0.140 & 0.141 & 0.160 & 0.288 & 0.289 & 0.313 & 0.311 \\
\hline Suceava & 0.238 & 0.248 & 0.263 & 0.181 & 0.348 & 0.345 & 0.372 & 0.295 \\
\hline Teleorman & 0.329 & 0.335 & 0.348 & 0.254 & 0.563 & 0.545 & 0.555 & 0.512 \\
\hline Timis & 0.148 & 0.141 & 0.149 & 0.144 & 0.197 & 0.186 & 0.207 & 0.227 \\
\hline Tulcea & 0.184 & 0.193 & 0.193 & 0.143 & 0.196 & 0.212 & 0.189 & 0.218 \\
\hline Valcea & 0.174 & 0.177 & 0.179 & 0.151 & 0.146 & 0.146 & 0.130 & 0.157 \\
\hline Vaslui & 0.266 & 0.276 & 0.281 & 0.211 & 0.421 & 0.439 & 0.435 & 0.431 \\
\hline Vrancea & 0.239 & 0.246 & 0.253 & 0.189 & 0.312 & 0.318 & 0.324 & 0.280 \\
\hline
\end{tabular}

Source: own computations

During the crisis absolute specialization (Herfindahl index) increased in most counties, especially in the ones already strongly specialized (Teleorman, Giurgiu, Botosani, Calarasi and Vaslui), but later fell back through economic recovery period. As regards structural dissimilarities between the counties and the national economy (measured by the Krugman index), the crisis and the subsequent recovery period brought about little change, except for a few counties (Table 1).

Figure 1 illustrates the regional resilience/weakness of the Romanian counties during the recent economic crisis (2008-2010), measured in two variants, based on employment (a) and GDP (b) data. Both indicators have been calculated as a ratio between the percentage decline in region $\mathrm{i}$ and average percentage decline at national level. Values above 1 indicate the vulnerable regions, being more adversely affected by the international economic crisis, while values below 1 point to resilient regions. 


\section{International conference on Research in MANAGEMENT}

Figure 1: Vulnerability to economic crisis in terms of employment decline (a) and GDP decline (b)

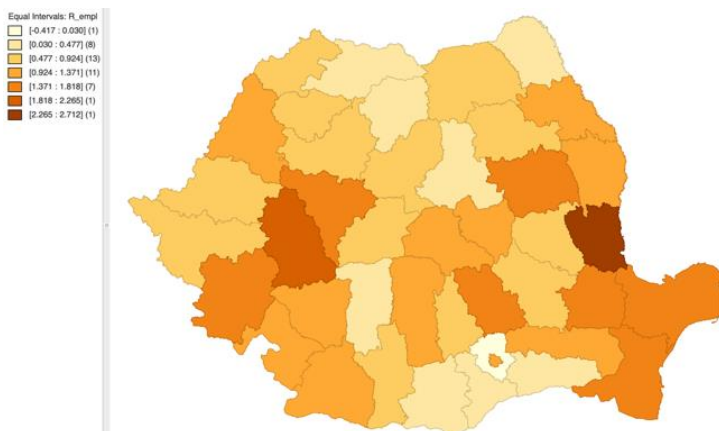

(a)
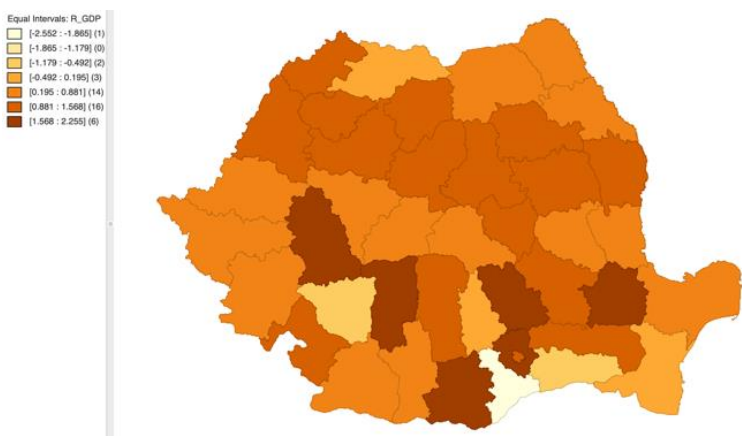

(b)

Source: own processing

The results reveal higher variation in resilience when measured in terms of GDP, compared to employment data. This is the consequence of a stronger decline in GDP than in employment during the crisis. At national level, the GDP dynamics during the crisis have been: $-5.9 \%$ in 2009 and $-2.8 \%$ in 2010 , while for employment the corresponding figures were much smaller: $-3.8 \%$ and $-0.47 \%$, respectively. It suggests labour hoarding, i.e. avoiding to lay-off all unnecessary employees when demand falls by adjusting the working schedule. By keeping the skilled and experienced personnel on the payroll, quicker recovery after the crisis and further growth are enabled.

Both maps in Figure 1 show clusters of counties having similar levels of resilience, which indicates spatial dependence among neighbour regions, thus the need to use spatial models. Therefore, we further regressed the resilience indicators against the specialization/diversification variables and control variables presented in previous section by testing the standard OLS model, as well as the spatial models described in equations (5) and (6).

Table 2 presents the results for the GDP resilience model. Moran's I and the standard tests related to spatial lag and spatial error models indicated that spatial dependence is not significant, and the classic model is the best fit for our data.

The Krugman dissimilarity index is negative and statistically significant (Table 2), suggesting that the more dissimilar to the structure of the national economy were the counties, the better they coped with the crisis, in terms of smaller GDP loss. Since no location quotient from the ones tested in this model managed to reach statistical significance, a finer disaggregation of economic sectors would be necessary for understanding which activities promoted this resilience. Unfortunately, such data was not available.

Table 2: Results for the GDP resilience model (Standard OLS Model)

\begin{tabular}{|l|l|l|l|}
\hline Variable & Coefficient & Std.Error & Probability \\
\hline CONSTANT & -3.37904 & 2.0851 & 0.11409 \\
\hline Herfindahl index & 9.19103 & 4.91862 & 0.07006 \\
\hline Krugman index & -2.79711 & 1.33702 & 0.04376 \\
\hline $\begin{array}{l}\text { Location } \\
\text { Quotient Trade }\end{array}$ & 1.16869 & 0.902097 & 0.20362 \\
\hline lnGDP/cap & 1.16081 & 0.397437 & 0.00608 \\
\hline
\end{tabular}


International conference on Research in MANAGEMENT

\begin{tabular}{|l|l|l|l|}
\hline InIndustrialisation & 1.24274 & 0.669647 & 0.07192 \\
\hline InEducation & -0.311828 & 0.114139 & 0.00980 \\
\hline Statistics & Value & Probability \\
\hline R-squared & 0.413067 & \\
\hline F-statistic & 4.10534 & 0.00319 \\
\hline Log likelihood & -40.7821 & \\
\hline Jarque-Bera test & 5.1500 & 0.07615 \\
\hline Breusch-Pagan test & 24.0592 & 0.00051 \\
\hline Moran's I & -0.0813 & 0.93521 \\
\hline
\end{tabular}

The Herfindahl index has the expected positive sign, indicating higher vulnerability in terms of GDP decline for strongly specialized counties, but the regression coefficient is statistically significant only if we relax a little the standard significance level of 0.05 . The same situation for the industrialisation variable, having a probability of 0.07192 . Industrialisation is measured as the share of all industries in overall employment of a county. The positive sign of this variable suggests that counties with a larger industry sector have been more vulnerable to the economic downturn. This is in accordance with the results obtained for another proxy for the development level, namely GDP per capita. GDP per capita is highly significant in this model and has a positive sign indicating that more developed counties lost relatively more economic activity. This was indeed the Romanian case and the main reason behind it was their stronger connectedness with the international markets. Developed counties are more dependent on international trade and foreign investment inflows, which dropped sharply during the crisis. On the other side, they were the ones recovering faster after depression, drawing on the same international links.

Human capital (proxied by the tertiary education graduates per 1000 inhabitants) is another highly significant variable and has the expected negative sign, indicating its adverse effect on GDP decline during crisis. It means the more educated the population, the more resilient was the regional economy to depression, confirming the positive role of human capital on economic performance.

The results for the employment resilience model are displayed in Table 3. In this case, the spatial error model is the best specification: the likelihood ratio test rejected the standard OLS model, while the log likelihood and other statistics have been better than the corresponding ones for the spatial lag model. The spatial error model reflects that each region is influenced by its neighbours in terms of unobserved variables that affect its employment resilience to depression. Omitting this influence would lead to estimation misspecification in the regression models. We also tested different spatial weights matrices and opted for a contiguity matrix, which provided the best results. It is a Queen 2 type matrix, accounting for spatial spill overs that extend to the second-order neighbours of each county (i.e. the counties with which it has a common border and their direct neighbours).

In the employment resilience model Herfindahl specialization index is no longer significant, but the Krugman dissimilarity index is and it keeps the same sign as in the previous model.

Table 3: Results for the employment resilience model (Spatial Error Model*)

\begin{tabular}{|l|c|c|c|}
\hline Variable & Coefficient & Std.Error & Probability \\
\hline CONSTANT & 2.73727 & 0.603045 & 0.00001 \\
\hline lnUrbanisation & 1.67779 & 0.293988 & 0.00000 \\
\hline Unemployment rate & 0.102419 & 0.0334547 & 0.00220 \\
\hline Location Quotient & -0.716491 & 0.383995 & 0.06206 \\
\hline
\end{tabular}


International conference on Research in MANAGEMENT

Budapest, Hungary

\begin{tabular}{|l|c|c|c|}
\hline Trade & & & \\
\hline Krugman index & -1.66985 & 0.490462 & 0.00066 \\
\hline $\begin{array}{l}\text { Lambda (spatial lag } \\
\text { errors) }\end{array}$ & 0.592755 & 0.213095 & 0.00541 \\
\hline Statistics & Value & Probability \\
\hline R-squared & 0.600962 & \\
\hline Log likelihood & -17.819087 & \\
\hline Breusch-Pagan test & 5.6815 & 0.22423 \\
\hline Likelihood Ratio Test & 4.6265 & 0.03148 \\
\hline
\end{tabular}

*Maximum Likelihood Estimation; Spatial Weights Matrix: Queen2

Another powerful and highly significant factor of influence is the urbanisation rate. Counties with large shares of urban population seem to be more vulnerable to employment decline caused by economic shocks. These are usually more developed counties, the ones that suffered bigger economic losses during the crisis due to their stronger connections with the international markets, as discussed previously for industrialisation and GDP per capita variables, in the context of the GDP resilience model.

The Location Quotient for Trade is less statistically significant, its probability being slightly over the 0.5 threshold. Its negative sign suggests that regions with larger trade activities managed to better withstand employment losses. Indeed, trade, which accounts for about $15 \%$ of Romanian economy, managed to go through the crisis without workforce downsizing at national level, although some negative adjustments have been made in several counties.

A significant factor of influence in the employment resilience model is unemployment rate, having the expected positive sign. This means that counties already having bigger unemployment rates at the beginning of the crisis were more vulnerable to employment shedding during the depression. High unemployment rates signal less efficient labour markets, having difficulties in absorbing the existing workforce and consequently it was harder for them to adjust to the shrinking demand during the crisis with little employment loss.

Finally, but not less important, the spatial lag of errors is highly significant and has a positive sign indicating similar outcomes in terms of high or low vulnerability to crises for neighbour counties. This indicates that the factors affecting employment resilience to economic shocks are not restricted within the regional borders, they tend to spill over to surrounding regions, creating spatial clusters of counties with similar resilience or vulnerability.

\section{Conclusion}

This paper tested and confirmed the hypothesis of resilience-inducing economic diversification for the case of the Romanian economy, using NUTS3 level data.

We found that more diversified regional economies were better at coping with the hardships triggered by the economic shock of the most recent international crisis. They seem to possess in a higher degree the desirable features for withstanding the pressures from the recession, among which the flexibility and adaptability promoted by diversification are key. This does not mean a total rejection of specialization, which has its own advantages, but an option for a more nuanced, careful and balanced design of regional economic policies. We believe that future regional strategy should promote economic diversification as a way of 


\section{International conference on Research in MANAGEMENT}

enhancing the ability to adapt faster to the difficulties generated by the economic shocks, while still harvesting local comparative advantages through smart specialization in key sectors.

Other factors of influence on resilience/vulnerability tested in our case study were largely in accordance with our expectations based on previous findings in the literature. We used three proxies for the level of regional development: GDP per capita, industrialisation and urbanisation rates. All of them indicated (even if in different models) higher vulnerability to economic shocks for the more developed counties, while the human capital reconfirmed its positive role on economic performance.

The limits of our research mainly ensue from the fact that we analysed the role of economic diversity from an aggregated regional perspective, while the actual decisions related to specializing/ diversifying the production arise from individual entrepreneurs. Our insights can inform government policies and strategies, but we need to be aware that firms' decisions are determined by peculiar situations and own constraints which are putting a specific mark on their actions.

\section{Acknowledgment}

This paper partially draws on the research undertaken within the PNCDI III project "ReGrowEU - Advancing ground-breaking research in regional growth and development theories, through a resilience approach: towards a convergent, balanced and sustainable European Union" (project number PN-III-P4-ID-PCCF-2016-0166), supported by a grant of the Ministry of Research and Innovation, CNCS - UEFISCDI. 


\section{International conference on Research in MANAGEMENT}

\section{References}

[1] Andrei, T., Iacob, A. and Vlad, L. (2007). "Tendencies in the Romania's Regional Economic Development during the Period 1991-2004", Economic Computation and Economic Cybernetics Studies and Research, no. 1-2, vol. 41, pp. 107-120.

[2] Anselin, L., Syabri, I., and Kho, Y. (2006). „GeoDa: An introduction to spatial data analysis". Geographical Analysis, 38, pp. 5-22.

[3] Bristow, G. (2010). "Resilient regions: re-'place'ing regional competitiveness", Cambridge Journal of Regions, Economy and Society, 3, pp.153-167.

[4] Cowell, M. (2013). "Bounce back or move on: regional resilience and economic development planning". Cities, 30, pp. 212-222.

[5] Cuadrado-Roura, J. R. and A. Maroto (2016). "Unbalanced regional resilience to the economic crisis in Spain: a tale of specialisation and productivity", Cambridge Journal of Regions, Economy and Society, 9, pp. 153-178, doi:10.1093/cjres/rsv034

[6] Davies, S. (2011). "Regional resilience in the 2008-2010 downturn: comparative evidence from European countries", Cambridge Journal of Regions, Economy and Society, 4, pp. 369-382.

[7] Di Caro, P. (2017). "Testing and explaining economic resilience with an application to Italian regions", Papers in Regional Science, vol. 96, is. 1.

[8] Dissart, J.-C. (2003). "Regional Economic Diversity and Regional Economic Stability: Research Results and Agenda", International Regional Science Review 26(4), pp. 423 446, doi: 10.1177/0160017603259083.

[9] Duranton, G. and Puga, D. (1999). "Diversity and specialisation in cities: Why, where and when does it matter?" Research Papers in Environmental and Spatial Analysis, 56.

[10]Feldman, M. and D. Audretsch (1999). "Innovation in Cities: Science-Based Diversity, Specialization and Localized Competition", European Economic Review, 43(2), pp. 409429.

[11]Fingleton B., Garretsen H. and Martin R. (2015). "Shocking aspects of Monetary Union: The vulnerability of regions in Euroland". Journal of Economic Geography, 15, pp. 907934.

[12]Florence, P.S. (1939). „Report of the location of industry”, Political and Economic Planning, London.

[13] Grossman, G. M. and Helpman, E. (1992). Innovation and growth in the global economy, Cambridge, Massachusetts: MIT Press.

[14] Hirschman, A.O. (1964). "The Paternity of an Index". The American Economic Review, vol. 54, pp.761-762

[15] Imbs, J. and Wacziarg, R. (2003). "Stages of Diversification", American Economic Review, vol. 93, no. 1, pp. 63-86.

[16] Jacobs, J. (1969). The economy of cities. New York, NY: Random House.

[17] Kaulich, F. "Diversification vs. specialization as alternative strategies for economic development: Can we settle a debate by looking at the empirical evidence?",

Development Policy, Statistics and Research Branch Working Paper 3/2012.

[18] Knott, A. M. (2003). "Persistent heterogeneity and sustainable innovation". Strategic Management Journal, 24(8), pp. 687-705.

[19] Krugman, P. (1991), Geography and Trade, MIT Press, Cambridge.

[20] Kuznets, S. (1971). "Modern Economic Growth: Findings and Reflections. Prize Lecture", Lecture to the memory of Alfred Nobel, December 11, 1971. 
[21] Moran, P. A. P. (1950). "Notes on Continuous Stochastic Phenomena". Biometrika. 37 (1), pp. 17-23. doi:10.2307/2332142

[22]Pede, V. O. (2013). "Diversity and Regional Economic Growth: Evidence from US Counties", Journal of Economic Development, 38(3), pp. 111-127.

[23] Traistaru I. and Pauna C. (2003). "The emerging geography in Romania”. In: Nijkamp P., Traistaru I., Resmini L. (eds) The economic geography in EU accession Countries, Aldershot: Ashgate, pp. 242-282.

[24] Wagner, J. E. and Deller, S. C. (1998). "Measuring the Effects of Economic Diversity on Growth and Stability". Land Economics, 74(4), 541.doi:10.2307/3146884

[25] Wagner, J.E. (2000). "Regional Economic Diversity: Action, Concept, or State of Confusion," The Journal of Regional Analysis and Policy, 30(2), pp. 1-22.

[26] Wennekers, S. and Thurik, R. (1999). "Linking entrepreneurship and economic growth". Small Business Economics, 13(1), pp. 27-56. 